\title{
A better understanding of cloud optical thickness derived from the passive sensors MODIS/AQUA and POLDER/PARASOL in the A-Train constellation
}

\author{
S. Zeng, C. Cornet, F. Parol, J. Riedi, and F. Thieuleux \\ Laboratoire Optique d'Atmosphérique, CNRS, UMR8518, Université Lille 1, Villeneuve d'Ascq, France \\ Correspondence to: C. Cornet (celine.cornet@univ-lille1.fr)
}

Received: 6 March 2012 - Published in Atmos. Chem. Phys. Discuss.: 8 May 2012

Revised: 30 September 2012 - Accepted: 2 November 2012 - Published: 3 December 2012

\begin{abstract}
Cloud optical thickness (COT) is one of the most important parameter for the characterization of cloud in the Earth radiative budget. Its retrieval strongly depends on instrument characteristics and on many cloud and environment factors. Using coincident observations from POLDER/PARASOL and MODIS/AQUA in the ATrain constellation, geographical distributions and seasonal changes of COT are presented, in good agreement with general cloud climatology characteristics. Retrieval uncertainties mainly associated to sensor spatial resolution, cloud inhomogeneity and microphysical assumptions are discussed.

Comparisons of COT derived from POLDER and MODIS illustrate that as the primary factor, the sensor spatial resolution impacts COT retrievals and statistics through both cloud detection and sub-pixel cloud inhomogeneity sensitivity.

The uncertainties associated to cloud microphysics assumptions, namely cloud phase, particle size and shape, also impact significantly COT retrievals. For clouds with unambiguous cloud phase, strong correlations exist between the two COTs, with MODIS values comparable to POLDER ones for liquid clouds and MODIS values larger than POLDER ones for ice clouds. The large differences observed in ice phase cases are due to the use of different microphysical models in the two retrieval schemes. In cases when the two sensors disagree on cloud phase decision, COT retrieved assuming liquid phase is systematically larger.

The angular biases related to specific observation geometries are also quantified and discussed in particular based on POLDER observations. Those exhibit a clear increase of COT with decreasing sun elevation and a decrease of COT in forward scattering directions due to sub-pixel in-
\end{abstract}

homogeneities and shadowing effects, this especially for lower sun. It also demonstrates unrealistic COT variations in the cloudbow and backward directions due to inappropriate cloud optical properties representation and an important increase of COT in the sun-glint directions in case of broken cloud.

\section{Introduction}

Cloud optical thickness (COT) is a key parameter to characterize cloud optical properties, which play an important role in the determination of cloud radiative forcing (Jensen et al., 1994; Kristiansen and Kristjansson, 1999). Some studies with GCMs simulations showed that the changes in COT result in negative radiative feedbacks as climate warms (Roeckner et al., 1987; Mitchell et al., 1989) while others showed positive feedbacks (Tselioudis and Rossow, 1994; Chang and Coakley, 2006). Long records of space-borne measurements at global scale are actually needed in order to correctly map COT and better understand the radiative effects of clouds on climate changes, especially in response to anthropogenic activities and natural variations (Rossow and Schiffer, 1991). COT is derived from the so-called solar reflective approach using a non water-absorbing band at visible wavelength under the assumption that the reflectance is a one-to-one nonlinear function of COT. A number of studies showed that this widely used method is practical and effective (King, 1987; Nakajima and King, 1990; Nakajima and Nakajima, 1994). However, because the method accuracy depends on different atmospheric and surface conditions, associated uncertainties 
need careful investigations. Errors can arise from spectral radiation calibration, radiative impact of the upper molecules, gas and aerosols, surface conditions, inappropriate cloud microphysics (especially cloud phase), horizontal and vertical cloud inhomogeneities, and so on. Some of these uncertainties have already been well qualified while others are not yet fully understood.

Concerning unsuitable cloud microphysics, departure in observed cloud phase function can lead to an uncertainty in COT of approximately 2 (Malkova, 1973). An error of a factor 2 in assumed water droplet radius can induce an error in COT of about $10 \%$ (Han et al., 1994) and for cirrus using a wrong particle shape can result in an over-estimation of COT by a factor that can exceed 3 (Mishchenko et al., 1996; Zhang et al., 2009). Due to the asymptotic shape of the relation between reflectance and COT, small uncertainties in reflectance can induce large errors in COT for thick clouds while uncertainties from the surface dominates the errors for thinner clouds (Platnick and Valero, 1995). Due to horizontal cloud inhomogeneities, the retrieved COT can be over or under estimated depending on cloud types, sensor resolution and observation geometries. For low spatial resolution, due to the so-called plan-parallel biases (Cahalan, 1994; Szczap et al., 2000), COT is generally underestimated. Observations of liquid clouds from AVHRR or POLDER show an important decrease in retrieved COT in forward directions, especially at oblique sun (Loeb and Coakley, 1998; Buriez et al., 2001), which is darkened by cloud-side shadowing in forward scattering viewing geometry. On contrary cloud-side illumination can lead to a positive bias in backscatter directions (Várnai and Marshak, 2002; Iwabuchi and Hayasaka, 2002). A better understanding and assessment of possible uncertainties are needed to obtain a better cloud climatology and also for the improvement of retrieval algorithms.

Many satellite sensors such as Advanced Very High Resolution Radiometer (Heidinger et al., 2005), Spinnig Enhanced Visible and Infrared Imager (SEVIRI) (Roebeling et al., 2006), MODIS (Platnick et al., 2003), and POLDER (Buriez et al., 1997) have developed their own algorithms. All these instruments have different spectral and spatial characteristics and different assumptions (microphysics, surface reflectance, etc.) are used in the retrieval associated algorithms. They have thus different strengths and limitations to retrieve COT and an assessment of these differences is required. In order to establish climate records of cloud cover properties, it is expected that merging of products derived from multiple sensors will be necessary. In addition, intercomparison of cloud products from different sensors can help in assessing the quality of each. This study was initially motivated by the global inter-validation of cloud products (including but not limited to COT) derived from the two different passive sensors (POLDER and MODIS) and secondly by the wish to understand and qualify differences observed, accounting for each sensor own characteristics. POLDER makes measurement of clouds in multiple direc- tions but with a quite low spatial resolution $(6 \mathrm{~km} \times 7 \mathrm{~km})$ whereas MODIS observes clouds with a higher spatial resolution $(1 \mathrm{~km} \times 1 \mathrm{~km})$ but only in one direction. Our assessment of COT for the two sensors in the paper is expected to give valuable information to the users of these satellites. This will contribute to establish long-term cloud climatologies with understood limitations and quantified uncertainties.

In a previous study, Zhang et al. (2009) discussed COT differences between POLDER/PARASOL and MODIS/AQUA for ice clouds. They concluded that differences could be principally related to the choice of microphysical model used in the algorithm. Here, we made more extensive comparisons of POLDER and MODIS COT for ice and also for water clouds. We discussed differences not only in terms of microphysical model but also in terms of sensor spatial resolution and viewing geometry. This work follows and is based on previous statistical comparisons of POLDER and MODIS cloud fractions and cloud thermodynamic phases (Zeng, 2011; Zeng et al., 2011).

In Sect. 2, we present quickly the POLDER and MODIS instruments, the algorithms used to retrieve COT and the products considered for our analysis. In Sect. 3, we show global comparisons of the two COT products. A discussion of potential uncertainties is provided in Sect. 4 according to spatial resolution, cloud microphysics and observation geometry. At last, conclusions and perspectives are given.

\section{Instruments characteristics, data and algorithms}

POLDER is a component of a series of sensors (Deschamps et al., 1994), developed by CNES (French Space Agency), flying on board PARASOL since 2004. It is a multispectral imaging radiopolarimeter designed to provide global and repetitive observations of the solar radiation and polarized radiance reflected by the Earth-Atmosphere system. The instrument design consists of a wide field of view $(1800 \mathrm{~km})$ telecentric optics, a rotating wheel carrying spectral filters and polarizers, and a CDD (Charged Coupled Device) array of detectors that induces a moderate spatial resolution of about $6 \mathrm{~km}$ at ground independent of the viewing angle. When it passes over a scene, POLDER acquires up to 16 successive multiangle measurements of both the total and polarized solar radiance in eight narrow bands from 443 to $1020 \mathrm{~nm}$ for daytime observations only.

MODIS is a 36-bands scanning spectroradiometer on board Aqua, launched in May 2002 as a part of NASA's Earth Observing System (EOS) (King et al., 1992). It provides 29 spectral bands at $1 \mathrm{~km}$ resolution, 5 bands at $500 \mathrm{~m}$ resolution and 2 bands at $250 \mathrm{~m}$ resolution. Its spectral coverage ranges from visible (VIS) to thermal infrared (IR) (0.415 to $14.235 \mu \mathrm{m})$. Cloud mask is based on a variety of tests using as many as 20 of these 36 spectral bands to maximize reliability of cloud detection. 
To determine COT, both the POLDER and MODIS operational algorithms employ the so-called plane parallel (PPA) and independent pixel cloud assumptions (IPA clouds) with the solar reflective method (Nakajima and King, 1990). The official product for POLDER is derived from the $0.67 \mu \mathrm{m}$ channel over land and $0.865 \mu \mathrm{m}$ channel over ocean (Buriez et al., 1997) while MODIS makes use of the $0.645 \mu \mathrm{m}$ band over land, the $0.858 \mu \mathrm{m}$ band over ocean and the $1.24 \mu \mathrm{m}$ band over sea ice or snow covered surfaces (Platnick et al., 2003). Concerning liquid clouds, MODIS algorithm uses a natural lognormal size distribution for water droplets with an effective variance of 0.13 while POLDER algorithm uses a gamma distribution with an effective variance of 0.15 . Optical properties are computed following Mie theory. The main difference comes from the values of the assumed particle effective radius, which vary for MODIS but are fixed in POLDER algorithm with only two distinct values over ocean and land. MODIS uses different particle sizes obtained from its water absorption channel in near-infrared range while POLDER, which has no particle size information, assumes clouds composed of water droplets with a constant effective radius of $9 \mu \mathrm{m}$ over land and $11 \mu \mathrm{m}$ over ocean (Buriez et al., 1997; Parol et al., 1999). For ice clouds, MODIS Collection 5 products are derived using the Baum05 Model (Baum et al., 2005) which consists in a mixture of different ice crystal habits. It uses 12 size distributions of crystals composed of mixed habits (droxtals, aggregates, bullet rosettes, hollow columns, solid columns and hexagonal plates) with the fraction of each habit depending on particle size. These habits definitions are based on in situ observations from the FIREII experiment. POLDER uses a fixed model, the Inhomogeneous Hexagonal Monocrystal Model (IHM) (C.-Labonnote et al., 2000, 2001), which assumes that light is scattered by randomly oriented hexagonal ice crystals containing air bubbles aimed at reproducing real crystals imperfections. Optical properties of a single crystal of $40 \mu \mathrm{m}$ with an aspect ratio of 2.5 are considered. Note that although the IHM model corresponds to a single particle size, it has been designed to provide an optimized global angular consistency of POLDER multiangle COT retrievals. For POLDER, the surface albedo and bidirectional reflectance over land are obtained from surface parameters previously retrieved from POLDER observations under clear-sky conditions by the POLDER "Land surfaces" processing line (Leroy et al., 1997) while over ocean it is calculated using the Cox and Munk (1956) model depending on the surface wind velocity derived from ECMWF analysis. For MODIS, the surface albedo is from 16-day 1$\mathrm{km}$ composites of clear-sky observations in MOD43 products (Strahler, 1999).

In the same way as for cloud fraction, the POLDER COT is first retrieved at the initial resolution of POLDER $\left(6 \times 7 \mathrm{~km}^{2}\right)$ for the 16 view directions. It is then averaged at the super-pixel resolution $\left(20 \times 20 \mathrm{~km}^{2}\right)$ to obtain a "directional" optical thickness (used in Sect. 4.3), which is afterward weighted averaged over the 16 directions and provides a mean COT and its standard deviation. Note that in this paper, in order to make easy comparisons with the MODIS product, we work only with the optical thickness, although using its multi-angular capability, a mean angular weighted spherical albedo is also derived for POLDER (Buriez et al., 2005).

The main differences between the POLDER and the MODIS processing lines that can affect the retrieved COT in case of thick clouds are thus the initial resolution (POLDER: $6 \times 7 \mathrm{~km}^{2}$, MODIS: $1 \times 1 \mathrm{~km}^{2}$ ), the differences in cloud microphysics assumptions and the ability of POLDER to observe different viewing geometries. MODIS has a higher resolution and provides particle size information. On the other hand, POLDER takes advantage of up to 16 viewing directions to provide an average optical thickness and to assess its angular consistency. Indeed, a large angular dispersion of retrieved COT can be attributed to the departure of POLDER observations from the microphysical assumptions or from single one layer PPA model (Parol et al., 2000). The optical thickness comparisons presented in the following are made at the POLDER super-pixel scale of about $20 \times 20 \mathrm{~km}^{2}$ using the PM (POLDER-MODIS) dataset, which contains both POLDER and MODIS level 2 official cloud products collocated and reprojected on a common sinusoidal grid (Zeng et al., 2011). POLDER single orbit files are used as reference for collocation of coincident MODIS granules. For each individual POLDER product orbit file, the sinusoidal grid used for collocation is centered at POLDER ascending node longitude. Optical thickness for both sensors is then averaged at $20 \times 20 \mathrm{~km}^{2}$ from the official level 2 products. Cloud fraction is determined directly for each instrument at their own initial level-2 product resolution that is from about $3 \times 3$ pixels for POLDER and $20 \times 20$ pixels (at nadir) for MODIS. Note also, that only $20 \times 20 \mathrm{~km}^{2}$ pixels that are classified overcast cloudy or partially cloudy by both instruments at the same time are considered for this study to limit impact of differences in cloud detection. The comparisons and results presented in this paper are for a full year period from December 2007 to November 2008 allowing sufficient sampling and representativeness with more than 100 millions of cloudy pixels.

\section{Results}

\subsection{Geographical distributions}

We first compare POLDER and MODIS COT through their geographical distributions and their differences (POLDER minus MODIS) for overcast (Cloud Fraction, $\mathrm{CF}=1$ for both sensors) clouds (Fig. 1). We present distributions for all overcast clouds (first line) and for overcast clouds separated by cloud phase classes. At first glance, one can notice that POLDER and MODIS show similar COT distributions regardless of cloud phase class. Note however that POLDER COTs are globally lower than MODIS ones (color scales are 


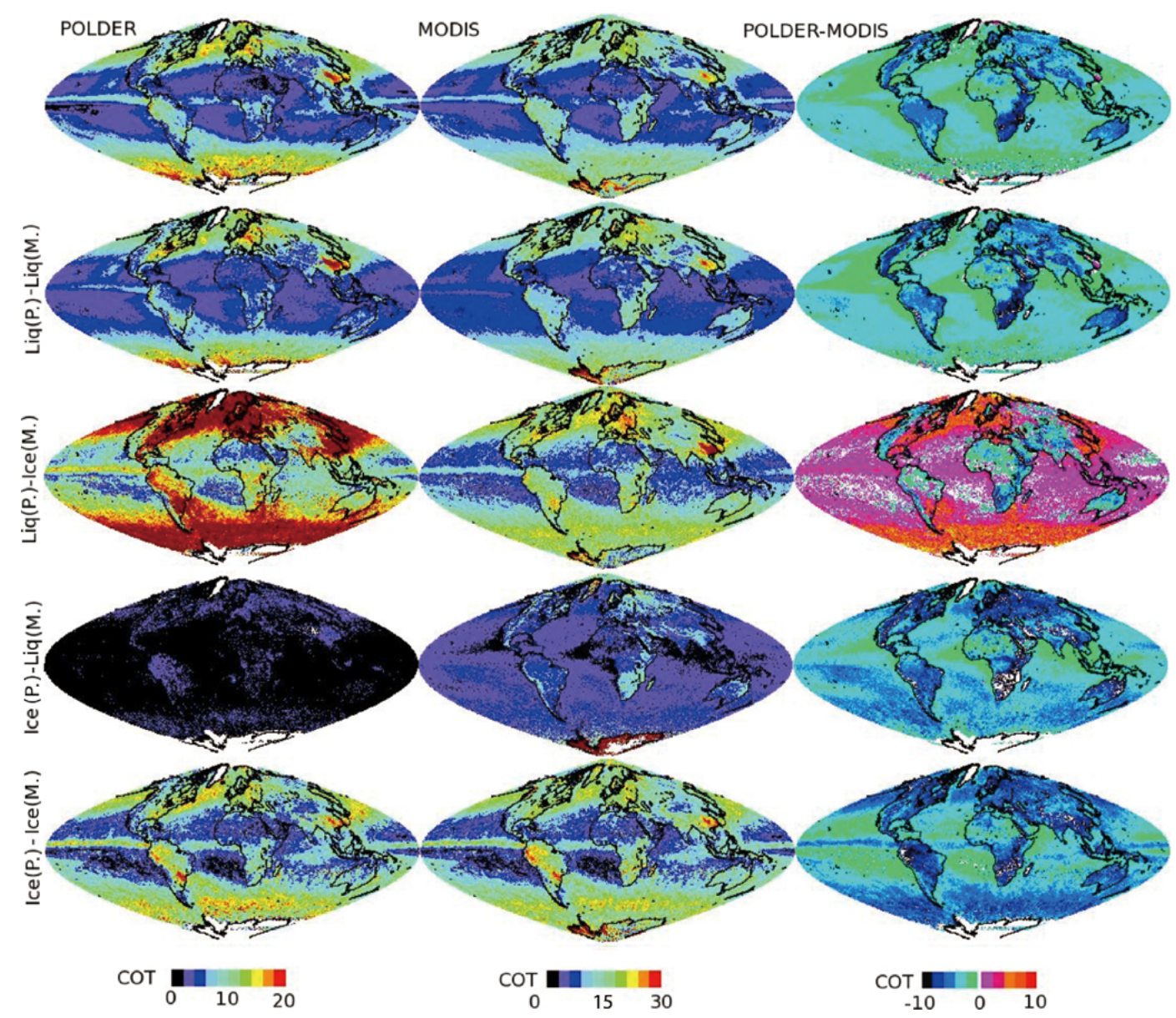

Fig. 1. Geographical distributions of mean POLDER COT (first column), MODIS COT (second column) and the corresponding COT differences (POLDER-MODIS) (third column) for all the clouds (first line) and clouds separated in 4 different phase classes: POLDER-liquid MODIS-liquid (second line), POLDER-ice MODIS-ice (third line), POLDER-liquid MODIS-ice (fourth line) and POLDER-ice MODISliquid (fifth line). Important note, for clarity reason, color scales are different for POLDER and MODIS COT.

not the same for POLDER and MODIS) except for the case POLDER-liquid/MODIS-ice. These differences will be discussed in Sect. 4.

Also and not surprisingly, the thickest ice clouds $($ COT $>20)$ are found mostly in the Inter Tropical Convergence Zone (ITCZ) and in the Storm Tracks (ST) zones over ocean and over northern South America, southern South Africa, southern Asia and eastern North America and principally over land. The thickest liquid clouds (COT $>20)$ are also found in these regions except in the ITCZ where convection processes are strong. Clouds are vertically extended and their tops are primarily composed of ice particle. Passive space-borne sensors in solar and thermal infrared range classify therefore them as ice even if water in liquid phase is present below.

Secondly, regardless of cloud phase, thicker clouds are found over continent for both POLDER and MODIS. This agrees with ISCCP C product but not with ISCCP D product where the land-ocean contrast of COT has been removed primarily because a significant increase in the amount of detected thin cirrus has been found over land with a lower IR threshold (Rossow and Schiffer, 1999). As we will see latter, error in phase identification for thin cirrus over liquid cloud can indeed lead to an artificial increase of COT. Moreover, low-level clouds over land can also extend to larger heights yielding larger optical thicknesses than low-level clouds over ocean (Warren et al., 1986, 1988).

For cases where POLDER and MODIS disagree on phase assumption, the POLDER-liquid/MODIS-ice class clouds have the largest COT and the POLDER-ice/MODIS-liquid class clouds tend to have the smallest COT. This suggests that the POLDER-liquid/MODIS-ice clouds are mostly linked to thick clouds in multilayer systems, for example very thin cirrus $($ COT $<2$ ) above liquid clouds (Zeng, 2011). In such situation, polarization features of underlying water cloud well marked with a strong signal in the cloudbow directions still appears in measured radiances, leading to identification of water phase corresponding to the lower layer. MODIS uses 

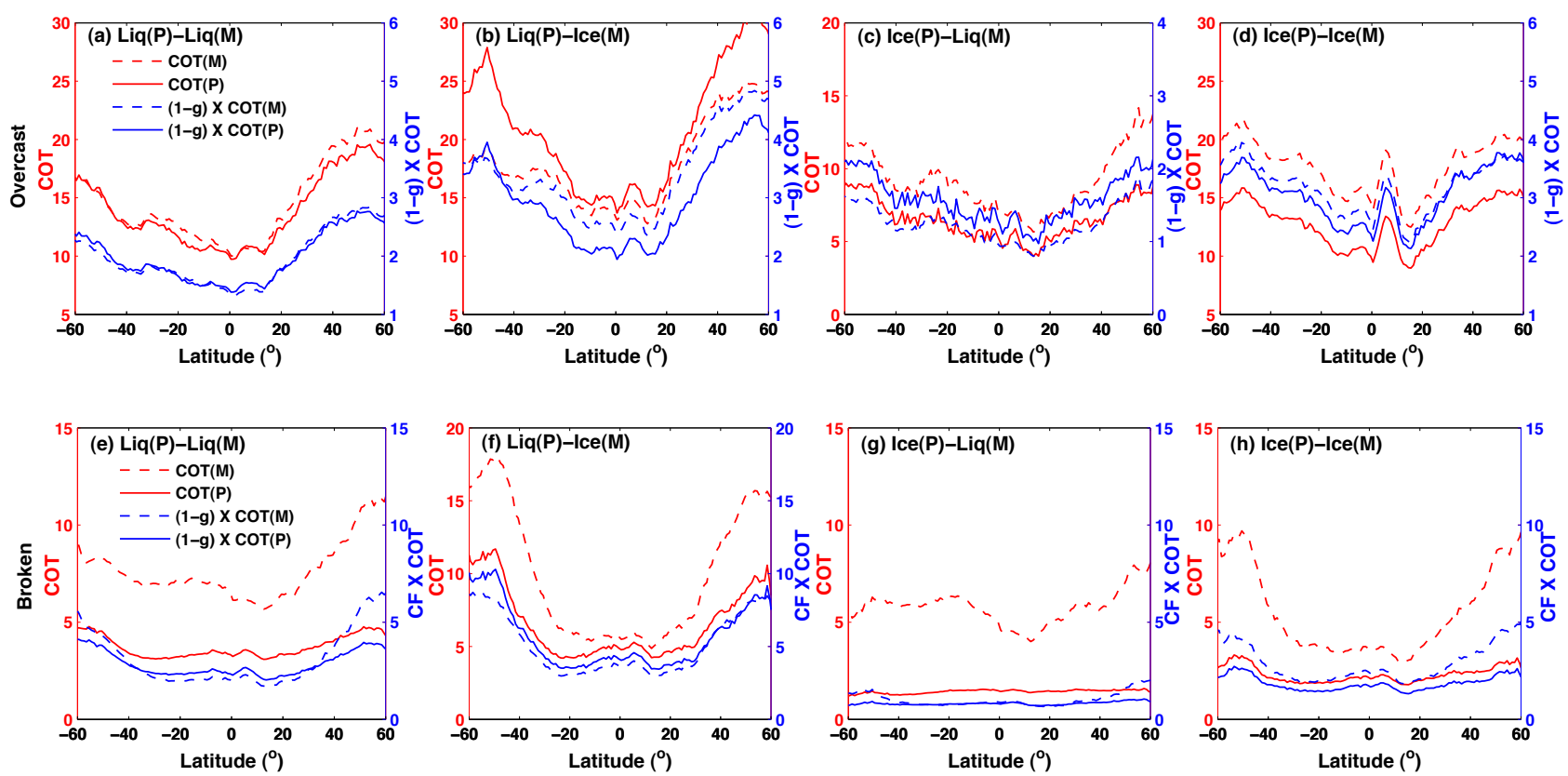

Fig. 2. First line: latitudinal variations of MODIS and POLDER COT (left axis: red) and the scaled COT calculated by $(1-g) \times$ COT (right axis: blue) for 4 different overcast clouds classes determined by cloud combined phase: POLDER-liquid and MODIS-liquid (a), POLDERliquid and MODIS-ice (b), POLDER-ice and MODIS-liquid (c), POLDER-ice and MODIS-ice (d). Second line: latitudinal variations of MODIS and POLDER COT (left axis: red) and the product CF $\times$ COT (right axis: blue) for 4 different broken clouds classes determined by cloud combined phases: POLDER-liquid and MODIS-liquid (e), POLDER-liquid and MODIS-ice (f), POLDER-ice and MODIS-liquid (g), POLDER-ice and MODIS-ice (h). In the legends, letter M stands for MODIS and letter P for POLDER.

IR channels as part of the phase algorithm decision, which on contrary, leads to ice phase identified as brightness temperature differences used are very sensitive to presence of elevated cold thin cirrus (Riedi et al., 2010). The POLDERice/MODIS-liquid phase is suggested to be associated to thin clouds or aerosols over low clouds (Waquet et al., 2009). The angular polarized signal of the ground or non-spherical aerosols is much closer to the ice clouds.

For unambiguous ice clouds, the COT differences are negative over the whole globe. The largest differences appear over land, in the ITCZ and the STs. For confident liquid clouds the differences are also negative in the STs and over land but appear negligible over ocean in tropics and middle latitudes with slightly positive differences in the ITCZ and around the continents especially around China where they may be associated with polluted air and smaller droplets. For POLDER-ice/MODIS-liquid phase clouds, COT differences are slightly negative almost all over the globe with quasizero values found over some tropical oceans. For POLDERliquid/MODIS-ice phase clouds, the differences are mostly positive over the entire globe, especially in the STs. These will be explained in Sect. 4.

In Fig. 2a to d, we present latitudinal variations of COT for overcast clouds for the four different cloud phase classes. We have also plotted latitudinal variations of the scaled optical thickness (King, 1987). "Scaled" $\left(\tau^{*}\right)$ means the opti- cal thickness $(\tau)$ is multiplied by the factor $(1-g)$ (Eq. 1), where $g$ is the asymmetry coefficient. This asymmetry coefficient $(g)$ is the ratio of the forward to the backward scattering (close to one means forward scattering with highly peaked phase function).

$\tau^{*}=\tau \times(1-g)$

The scaled optical thickness depends thus less on cloud microphysical assumption (cloud phase, cloud particles radius and shapes) and almost only on surface albedo and cloud reflection. This formulation allows to account partially for the different assumed microphysics in POLDER and MODIS retrievals (see Sect. 4.2). The latitudinal distributions of COT for ice or liquid clouds have similar trends with large values in the Storm tracks zones and small values in the subtropics. As already mentioned, we see that ice and liquid COT have a different behavior in the ITCZ with larger values for ice clouds, which does not appear for liquid clouds. Confident single layer liquid clouds (i.e. without overlaying ice clouds) are rarely occurring in the ITCZ and result statistically in small mean liquid COT in this zone. COT of confident liquid clouds derived from POLDER is very similar to MODIS with maximum relative differences smaller than $10 \%$ (Fig. 2a). For confident ice clouds, the POLDER COT is on average smaller than the MODIS one with an almost constant difference of 5 (Fig. 2d). For clouds with inconsistent phases determined, we see that the sensor using the liquid cloud model 

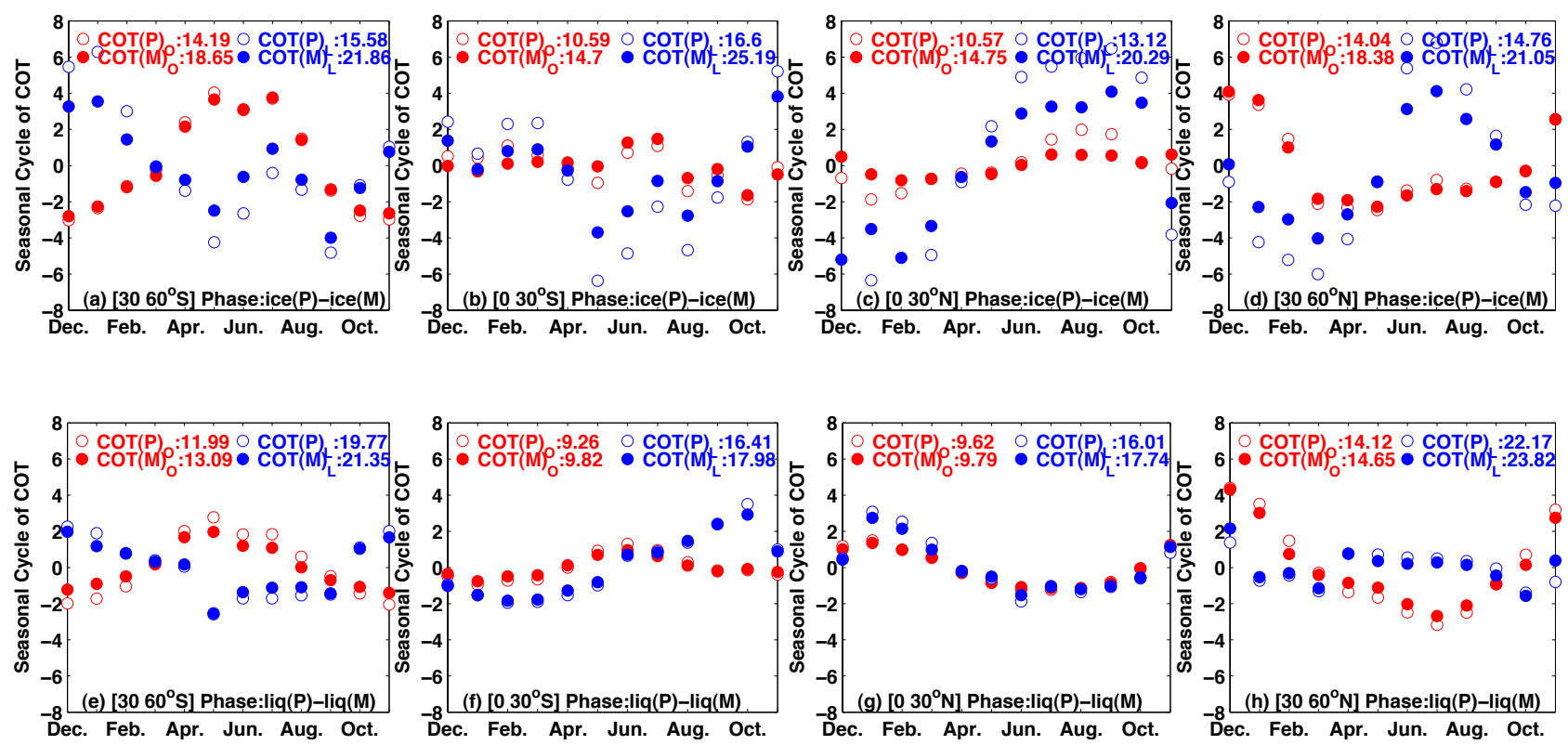

Fig. 3. Seasonal cycles of COT for overcast clouds over South Hemisphere mid-latitude regions ( $\left.30-60^{\circ} \mathrm{S}\right)$ (first column) and tropical regions $\left(0-30^{\circ} \mathrm{S}\right)$ (second column), over North Hemisphere tropical regions $\left(0-30^{\circ} \mathrm{N}\right)$ (third column) and mid-latitudinal regions $\left(30-60^{\circ} \mathrm{N}\right)($ fourth line) with different combined cloud phases: POLDER-ice and MODIS-ice (first line), and POLDER-liquid and MODIS-liquid (second line). Ocean data are in red and land data in blue. The solid circles present data from MODIS and the hollow circles from POLDER. The values in the figures correspond to annual mean COT in the regions.

always provides larger COT than the other using ice cloud model (Fig. $2 b$ and c). We note also that, in case of POLDERliquid/MODIS-ice phase class clouds (Fig. 2b), both COTs increase polewards as thicker cloud are found in the storm tracks. However, POLDER COT increases more rapidly than MODIS ones. As we will discuss in Sect. 4.2, here positive COT difference (POLDER-MODIS) primarily comes from different asymmetry factor used in the retrieval, which is associated with cloud phase and effective radius.

Figure $2 \mathrm{e}$ to $\mathrm{h}$ present latitudinal variations of COT for broken clouds. Broken clouds correspond to the cases where both sensors indicated broken clouds $(0<\mathrm{CF}<1)$. For these clouds, COT values are logically reduced compared to overcast clouds as clear sky part should often be present in the sub-pixel scale. For any phase class, we note that the MODIS COT is larger than the POLDER one. Differences between the two COT are a lot reduced when multiplied by CF (blue curves). We will discuss this point in Sect. 4.1. In addition, we note that POLDER COT presents smaller latitudinal variations than the MODIS one, which increase towards high latitudes. As POLDER has a lower resolution and multiangle observation capability, POLDER CF tends to be less sensitive to sub-pixel cloud fraction and most of subpixel holes are not seen regardless of the latitude, generally leading to higher cloud fraction in broken condition and therefore to smaller optical thickness. MODIS with its higher spatial resolution characterizes more fractional clouds and thus finds thicker and more fractional clouds towards the high latitudes.
This is consistent with the fact the product COT $\times \mathrm{CF}$ shows closer variations.

\subsection{Seasonal cycles}

The seasonal cycles of COT are plotted in Fig. 3 for MODIS and POLDER, separately for land and ocean. We subtract the annual mean COT from the monthly average in order to remove the systematic bias that exists between the two COT and focus on seasonal variability analysis. The seasonal cycle is calculated for overcast clouds for both POLDER and MODIS sensors according to cloud occurrence regions (i.e. subtropics and middle latitudes over ocean and land in each hemisphere) and to their combined thermodynamic phases. From the figures, we first see that the COTs from the two sensors depend logically on the seasons and regions. For a same region and with a consistent thermodynamic phase, MODIS and POLDER COTs have quite similar temporal variations, especially for clouds with consistent liquid phase (Fig. 3e to h). For liquid clouds (Fig. 3e to h), COT shows almost asymmetrical characteristics in South and North Hemispheres over both land and ocean, with thicker clouds in winter of each hemisphere. This agrees well with ISCCP climatology (Rossow and Schiffer, 1999; Rossow et al., 1989). The only noticeable exception is over land in the mid-latitude of South Hemisphere certainly because of smaller sample. For ice clouds (Fig. 3a to d) in both hemispheres, seasonal variations are more pronounced with differences between ocean and land. Clouds are thicker over ocean in winter of the 

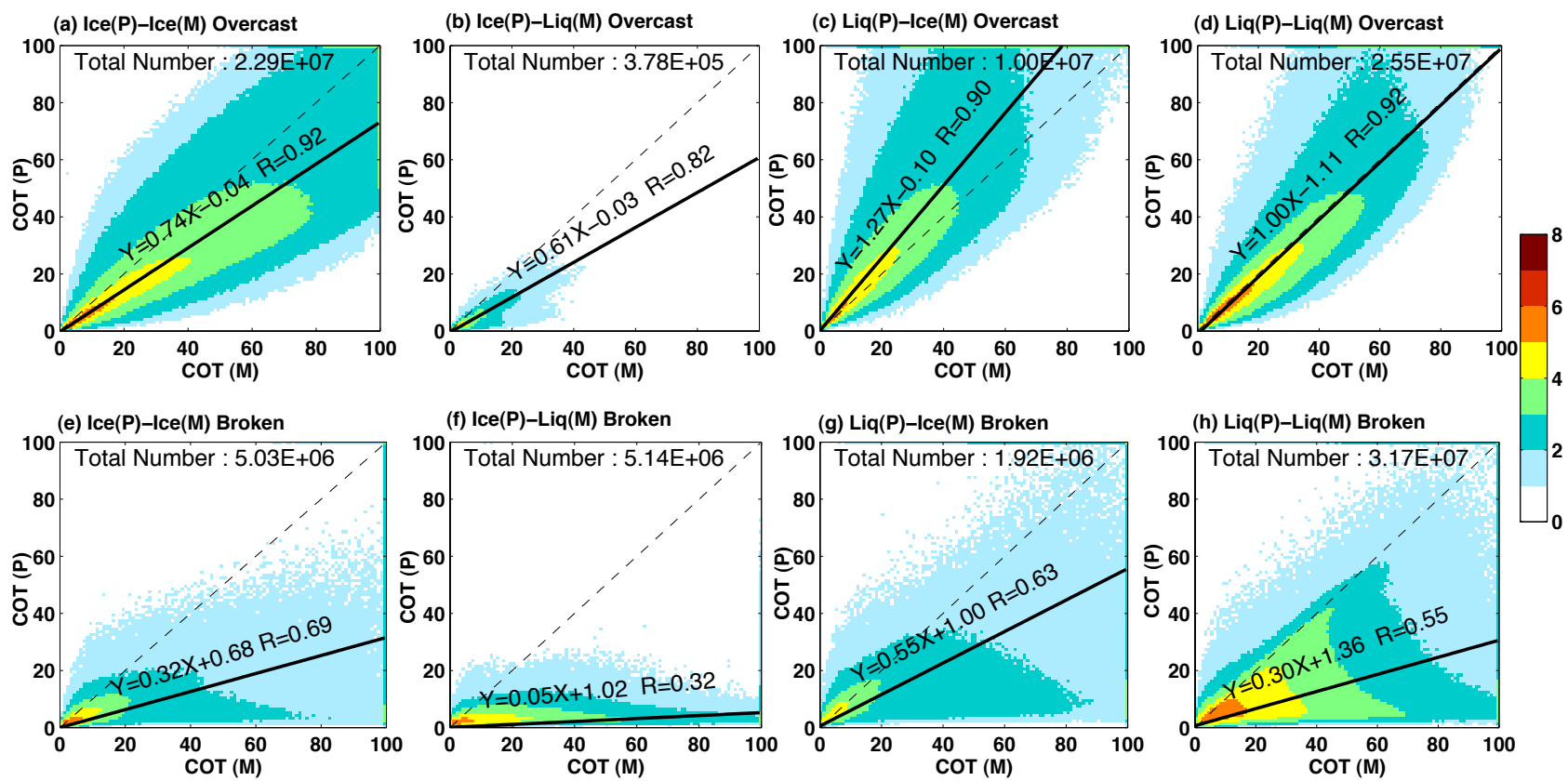

Fig. 4. Two-dimensional histograms of POLDER and MODIS COT for 4 different classes of overcast and broken clouds over ocean. They are separated by cloud combined phase. Color scale on the right represents the logarithm of the pixel number. Dashed lines are the one-toone function lines meaning the POLDER COT equal to the MODIS one. Solid lines are the computed linear regression functions between POLDER (y-axis) and MODIS (x-axis) COT, with slopes and correlation coefficients $(R)$ labeled above the solid lines.

two hemispheres and over land in summer of the two hemispheres. The first may be attributed to frontal system depressions and winter storms. Over land in summer, thicker clouds may be associated to convection that develops in the early afternoon.

\subsection{Pixel-to-pixel comparisons}

We now show pixel-to-pixel comparisons between the COTs of the two sensors. Comparisons are analyzed in term of slope and correlation coefficient of the linear regression assuming linear relationship between the two dataset. These two parameters give a measure of the pertinence of the linear relationship and should be equal to one for perfect relation.

Among all conditions, overcast scenes over ocean can be considered as ideal situations for retrieving COT. Selecting these clouds, we plot the one-year statistical two-dimensional histograms of POLDER and MODIS COTs for four different combined thermodynamic phase classes (Fig. 4a to d) to show COT relationship between the two sensors. Overcast condition is determined as previously from combination of POLDER and MODIS. In these figures, we first note that in overcast cases (corresponding to $5.88 \times 10^{7}$ pixels), most clouds have the same phases determined by both sensors: $82 \%$ pixels are in agreement with $43 \%$ detected as liquid and $39 \%$ detected as ice by both sensors. For the four different phase classes, the correlation coefficients are quite important with values greater to 0.8 and even above 0.92 when the two sensors agree on phase index (confident ice and liquid clouds). These results show that there is a strong linear relationship between POLDER and MODIS COTs. The slope is very good with value close to the unity for liquid water clouds but is only about 0.74 for ice clouds. For clouds with inconsistent phases between the two sensors (Fig. 4b and c), both slopes and correlation coefficients are logically worse compared to consistent phase cases (Fig. 4a and d). We also notice that the slope of the POLDER-ice/MODISliquid clouds (Fig. 4b) is below one, which means that the MODIS COT is larger than the POLDER one. On contrary, the slope of the POLDER-liquid/MODIS-ice clouds (Fig. 4c) is greater than one, which means that the POLDER COT is larger than the MODIS one. These results illustrate again, if needed, that a correct identification of phase and microphysics is critical for COT retrieval. We will discuss more precisely these differences and their associated impacts in Sect. 4.2.

Comparisons between the two sensors for broken clouds are shown in Fig. 4 (e to h). Slightly less broken clouds $\left(4.38 \times 10^{7}\right.$ pixels are broken compared to $5.88 \times 10^{7}$ overcast) are selected. POLDER and MODIS agree on the phase detection for $83 \%$ of the cases and the majority of broken clouds ( $72 \%$ of the cases) have liquid phase. For broken clouds, the mean COT at super-pixel scale is computed by averaging the COT of the cloudy part. Regardless of thermodynamic phases, we find out that the correlation coefficients are typically smaller than 0.7 for broken clouds. The slopes are 
entirely below 1 with POLDER detecting much smaller COT. Compared to overcast conditions, at first appearance, the relationships between COTs from the two sensors seem thus to be much worse. Cloud detection is indeed more difficult for broken cloud scenes and some disagreements on cloud fraction between the two sensors can explain the COT differences for broken clouds. As discussed in Zeng et al. (2011), cloud fraction disagreement is due to the difference in the sensor spatial resolutions, to the misclassification of heavy aerosols loadings or to a bad detection of thin cirrus. This impact of sensor spatial resolution and its consequence results on COT retrieval will be discussed in Sect. 4.1.

\section{COT retrieval uncertainties}

\subsection{Impact of the sensor spatial resolution}

As already described, COT is only retrieved for the pixels detected as cloudy and the final COT is averaged at the super-pixel level considering only the cloudy pixels. Internally, the correctness of cloud identification can therefore strongly impact COT retrieval. MODIS with a higher spatial resolution identify much smaller clear scenes among clouds than POLDER. Consequently, for regions of fractional cloud cover, the POLDER cloud cover is larger than the MODIS one (Zeng et al., 2011). However, in such cases, except over bright surfaces, the reflectance used for the POLDER COT retrieval is reduced by the sub-pixel holes among clouds and the derived COT is thus smaller compared to the MODIS one. It is clearly identifiable in Fig. 4 (e to h) where the POLDER COT is much smaller than the MODIS one. This bias directly associated to cloud identification can be attributed to the sensor resolution difference. In order to account for it, we present in Fig. 5 the pixel-to-pixel comparisons of the product COT $\times$ CF for broken clouds. Compared to Fig. 4 (e to h), which show pixel-to-pixel comparisons of COT for the same cases, it is clear that both the correlation coefficients and the slopes of the relationship have been greatly improved for all phase classes. Linear regressions with higher confidence are much closer to the first bisecting line. This is also confirmed by the curves of the product COT $\times \mathrm{CF}$ in Fig. $2 \mathrm{e}$ to $\mathrm{h}$.

To go further, in Fig. 6a, we also plot for liquid oceanic clouds the two constants (slopes and correlation coefficients) of the relationships between COT and the product $\mathrm{COT} \times \mathrm{CF}$ as a function of MODIS cloud cover. It is clear that both the slope and the correlation coefficient for the COT relationships increase with cloud fraction almost linearly. Smaller cloud cover leads to larger dispersion, corresponding to weaker relationships between the two sensors products. Looking at the product $\mathrm{COT} \times \mathrm{CF}$, we notice that the slope is a lot improved (closer to unity) and less dependent on cloud cover. However, the correlation coefficient is just slightly improved and still increases with cloud cover
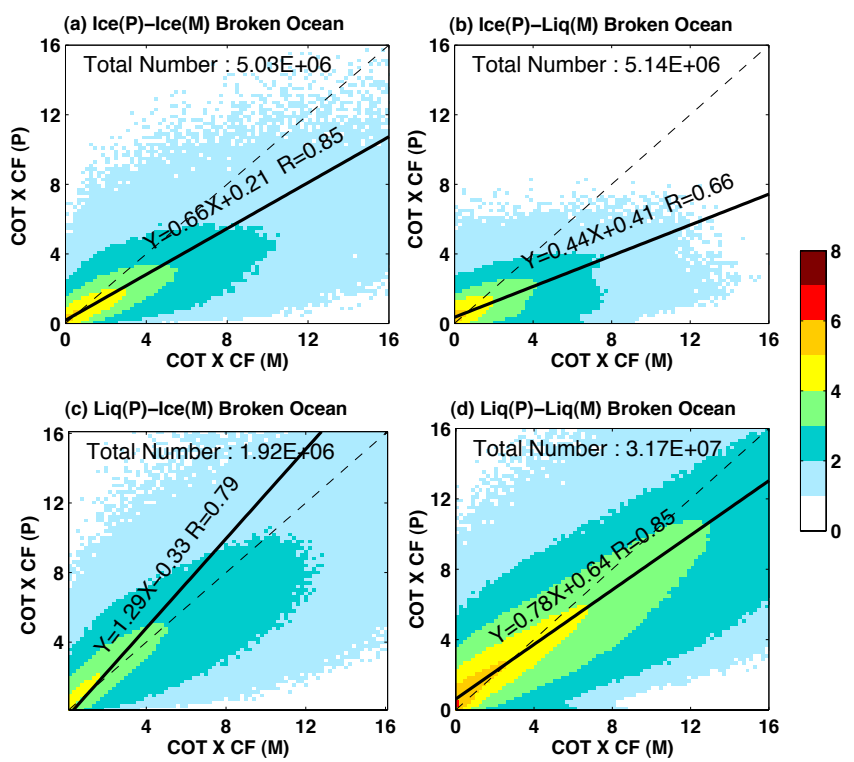

Fig. 5. Two-dimensional histograms of the product $\mathrm{COT} \times \mathrm{CF}$ of 4 different broken clouds over ocean separated by cloud combined phase. Color bars represent the logarithm of the pixel number. Dashed lines are the one-to-one function lines meaning the POLDER COT equal to the MODIS one. Solid lines are the computed linear regression function of POLDER (y-axis) and MODIS (x-axis) COT $\times \mathrm{CF}$, with slopes and correlation coefficients $(R)$ labeled above the solid lines.

showing that COT retrieval is anyway less reliable in case of broken cloud fields.

These results stress out again that the sensor resolution affects the COT retrieval via the cloud cover difference and that COT values should not be used without knowledge of cloud fraction. This well known mechanism should absolutely be accounted for when building statistics on cloud cover from multi-sensor dataset.

In addition, compared to MODIS, POLDER with a lower resolution ignores not only the sub-pixel cloudiness but is also less sensitive to some of the sub-pixel cloud inhomogeneities. When POLDER considers a cloudy pixel at a $6 \mathrm{~km} \times 7 \mathrm{~km}$ resolution, MODIS with a pixel resolution of $1 \mathrm{~km} \times 1 \mathrm{~km}$ accounts for a part of the sub-pixel variability. The convex nature of the reflectance-COT relationship implies that the mean COT of two cloudy pixels is larger than the effective COT derived from the mean reflectance of the two pixels (Cahalan, 1994; Szczap et al., 2000). Therefore, COT retrieved from the average reflectance of the pixels is smaller than the linear average value. As POLDER cannot account for the sub-pixel heterogeneities, the POLDER COT is expected to be smaller than the MODIS one. To observe this, in Fig. 6b, we present correlation coefficients and slopes between POLDER and MODIS COTs for different inhomogeneity parameters, which are determined as the ratio of the standard deviation to the mean COT computed from MODIS 

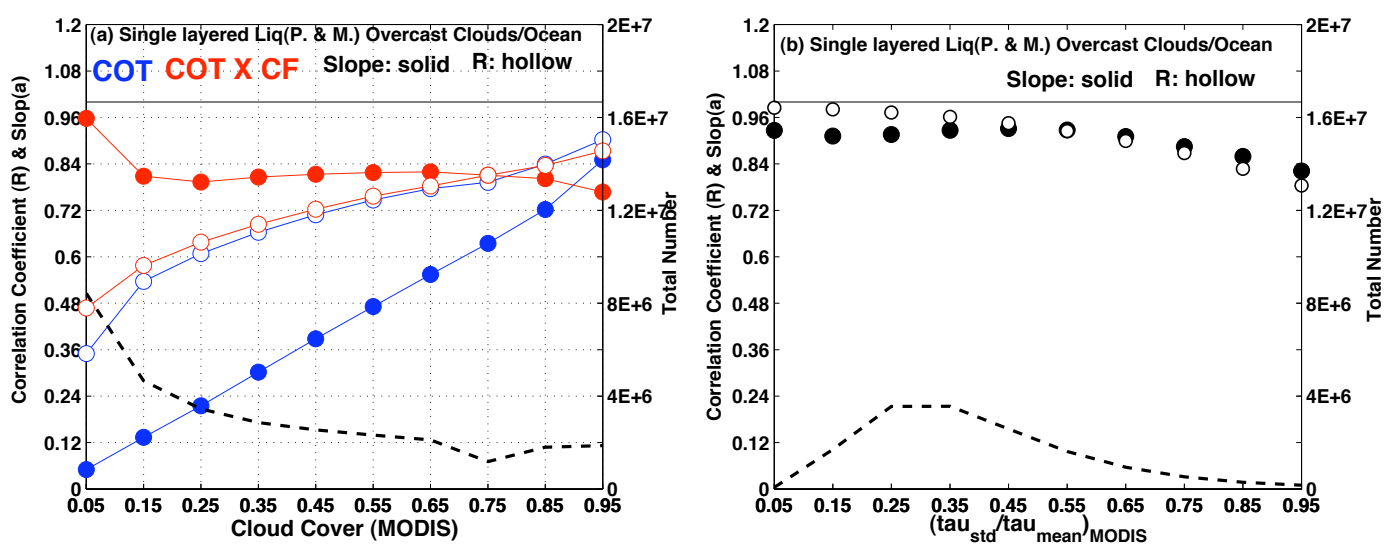

Fig. 6. Slopes and correlation coefficients, $R$, of the relationship between POLDER and MODIS COT in blue and between POLDER and MODIS COT $\times$ CF in red in function of MODIS cloud cover (a). Slopes and correlation coefficients of the relationship between POLDER and MODIS COT in function of cloud inhomogeneity from MODIS (b). Only the liquid overcast (for POLDER and MODIS) clouds over ocean are considered. Dashed curves represent the number of samples in each case.

product. We see for homogeneous clouds (inhomogeneity parameter close to 0 ), that both the correlation coefficients and the slopes values are high and close to one. When clouds become more inhomogeneous, these two constants decrease steadily. It means that the more inhomogeneous the clouds are, the smaller the POLDER COT compared to the MODIS one and the weaker the coherence between the two are. Keep also in mind that when sub-pixel cloud inhomogeneities are important for the two sensors, the COTs retrieved from the two are underestimated.

\subsection{Impact of cloud microphysics}

Another important factor that impacts the retrieved COT concerns the choice of the microphysical model, in particular the associated scattering phase function. As shown in Zeng (2011), POLDER and MODIS may have inconsistent phase decisions but even in case of consistent phases, they use different particle microphysical model to retrieve COT, especially for ice clouds where different microphysical models are used (see Sect. 2). For water cloud, the main difference comes from the particle size which is fixed for POLDER (9 $\mu \mathrm{m}$ over land and $11 \mu \mathrm{m}$ over ocean) and determined from its near-infrared channel for MODIS. To account for these differences in a first order, we introduce the scaled optical thickness (King, 1987) (Eq. 1). The potential optical thickness bias associated to the uncertainties of scattering model is assessed by comparing for overcast clouds over ocean the relationships of the scaled optical thickness between the two sensors in Fig. 7 and the relationships of optical thickness of the same clouds in Fig. 4a to d.

Looking at Figs. 4 and 7 corresponding to different phase decisions (Figs. $7 \mathrm{~b} / 4 \mathrm{~b}$ and $7 \mathrm{c} / 4 \mathrm{c}$ ), we see a great improvement between the two scaled COTs which means that a significant part of the differences between POLDER and MODIS are directly linked to an important factor con-
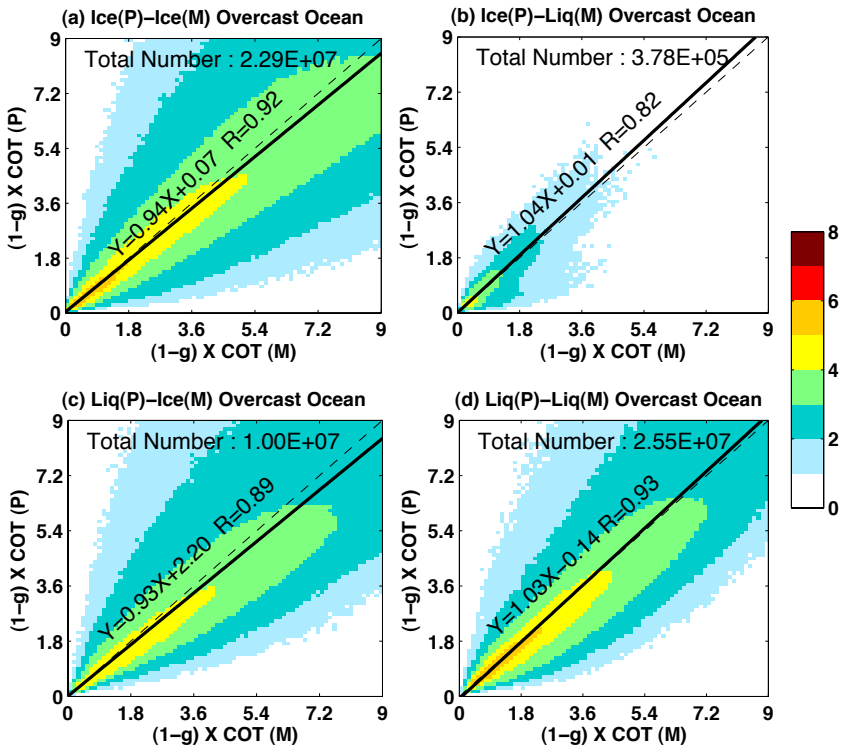

Fig. 7. Two-dimensional histograms of the product COT $\times(1-g)$ for the 4 different overcast clouds over ocean separated by cloud combined phase. Color bars represent the logarithm of the pixel number. Dashed lines are the one-to-one function lines meaning the POLDER COT equal to the MODIS one. Solid lines are the computed linear regression functions of POLDER (y-axis) and MODIS (x-axis) scaled COT, with slopes and correlation coefficients $(R)$ labeled below the solid lines. Note that figures axis are limited to upper values of 9 corresponding to COT of about 60 in Fig. 4.

cerning inconsistent phase determination. Indeed, backward scattering for ice crystals is much stronger than for water droplets $\left(g_{\text {ice }}<g_{\text {water }}\right)$. Thus, to reflect the same quantity of radiation back to satellites, COT of ice clouds need to be smaller compared to water clouds. This being considered, it is fairly straightforward to understand that the slope 
for POLDER-ice/MODIS-liquid class clouds (Fig. 4b) is below one and the slope for POLDER-liquid/MODIS-ice class clouds (Fig. 4c) is larger than one. As the use of scaled optical thicknesses (using corresponding asymmetry factor) partially removes dependence on microphysics assumption, closer relations between the two sensors are found for the inconsistent phase cases in Fig. 7 (b, c) compared to Fig. 4 (b, c) and the slopes of scaled optical thickness are much closer to unity.

For overcast clouds with consistent phases over ocean (Fig. 4a and d), where the smallest bias are expected from cloud detection, phase identification and surface impact, COT is retrieved with a higher accuracy and confidence from the two sensors. COT relationships between them should appear better with both slope and correlation coefficient closer to unity. That is confirmed for confident liquid cloud cases but not for confident ice cloud cases where the correlation coefficient is good but the slope value is biased away from one. Note, when liquid clouds get thicker, POLDER COT appears larger than MODIS one. This is an artifact because MODIS algorithm uses an upper limit of 100 for COT retrieval, while POLDER COT has no upper limit with values as large as 200. The averaging process at the POLDER superpixel scale leads therefore to higher values for POLDER than for MODIS. In addition, for large COTs, the dependence of reflectance on COT becomes weaker, so small changes in radiances lead to large changes in COT.

For liquid clouds, both sensors employ a Mie scattering model. POLDER has no real-time effective radius retrievals but uses a fixed value of $9 \mu \mathrm{m}$ over land and $11 \mu \mathrm{m}$ over ocean whereas MODIS uses the effective radius retrieved from the near-infrared band. Consequently, the asymmetry parameter $(g)$ is constant for POLDER but increases with particle size for MODIS. However, as the sensitivity of visible reflectance of liquid clouds to particle size is small, the impact of effective radius bias on the POLDER COT deviation can be most of the time ignored except for particular scattering angles, such as in cloudbow and backward directions (Parol et al., 2000; Buriez et al., 2001). The good statistical relationship between the liquid COTs of the two sensors in Fig. $4 \mathrm{~d}$ is thus not really improved for the scaled COT in Fig. 7d.

COT retrieval for ice clouds is complex because it depends on the microphysical models used, which, contrary to water droplets, presents a large diversity in terms of shape and size. The strategy followed in the algorithm of MODIS and POLDER is completely different (Zhang et al., 2009). PODLER used a fixed ice cloud model, the IHM (Inhomogeneous Hexagonal Monocrystal) model, which was found to match, at the best, angular measurements of ice clouds made by POLDER. That implies the shape, size and thus phase function used in the POLDER algorithm is constant. MODIS, which used several models built from in-situ observations of cirrus clouds, used variable ice particle distributions with their sizes determined by its near infrared channel.
The slope obtained in Fig. 4a for a whole year at the global scale (0.74) is close to the value found by Zhang et al. (2009) for only one granule (0.68). The better slope $(0.74$ compared to 0.68 ) and correlation coefficient obtained may be partially due to the improvement in the matching of POLDER and MODIS coincident pixels in PM data, but also to the more extensive statistics used for the present studies. COT is smaller for POLDER compared to MODIS because they use different phase functions with an asymmetry factor of 0.766 for POLDER and a value between 0.775 and 0.8808 for MODIS at $865 \mathrm{~nm}$. For MODIS, less energy is thus returned backward and the optical thickness of the cloud needs to be higher to match the measurement.

Comparisons to optical thickness for ice clouds, the scaled optical thicknesses leads to closer relations between the two sensors with the slope value much closer to one (Fig. 7). These statistical results confirm that the bias in ice cloud optical thickness between POLDER and MODIS comes mainly from cloud microphysical assumptions as reported by Zhang et al. (2009). These results further stress out the critical need for a better knowledge of ice clouds asymmetry parameter if we aim at a consistent description of ice cloud properties on global scale for climatological purposes.

\subsection{Impact of the observation geometry}

In this section, we go a little further to analyze POLDER and MODIS COT and look at the bias associated to the observation geometry already highlighted by many other works (e.g. Loeb and Coakley, 1998; Buriez et al., 2001; Iwabuchi and Hayasaka, 2002). During the retrieval process, some assumptions have to be made either for simplicity and computational speed or because not enough information content is available from the data. If the cloud model was perfect and geographical samples were sufficient and unbiased, COT values should be almost constant with viewing angles. However, we see in Figs. 8 and 9 where polar graphs of COT as a function of sensor zenith and relative azimuth angle between the sun and the sensor are represented, that there are important angular variations. Polar graph allows to identify some deviations due to the inappropriate cloud model used for the retrieval. In addition, it can help to establish a reference to determine a suitable weighted average method or to select the direction in order to obtain the best final COT from directional COT. Hence, it is possible to avoid some systematical errors coming from 3-D effects, for example, shadow effect. Note that a weighted angular method is already applied to derive the cloud spherical albedo and the optical thickness from the POLDER data (Buriez et al., 2005). In Fig. 8, we present 2-dimentional polar graphs of both MODIS-derived COT for overcast liquid clouds of all sun incidences and POLDER-derived COT for overcast liquid clouds of all sun incidences and of different classes of sun incidences. In Fig. 9, we present the same figures, for broken liquid clouds. The zero relative azimuth direction 

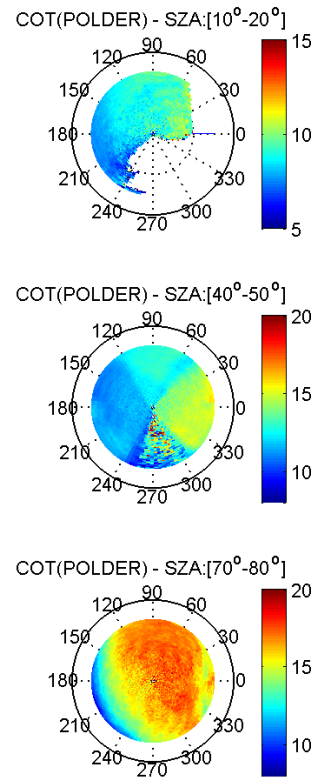
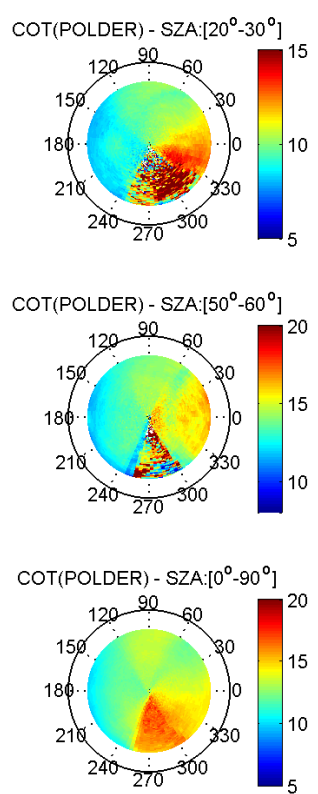
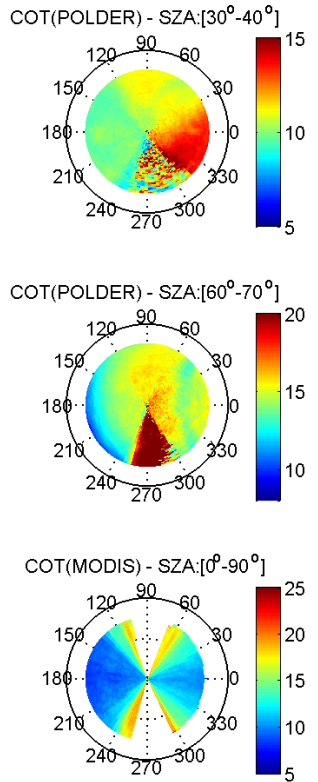

Fig. 8. Polar graphs of POLDER COT for overcast oceanic liquid clouds for different solar zenith angles (1st, 2nd lines and the 1st column of the 3rd lines) and of MODIS COT for all sun incidence angles (lower right corner). Polar angle represents relative azimuth angle between the satellite and the sun (from $0^{\circ}$ corresponding to backscattering direction to $359^{\circ}$ ). Polar radius corresponds to the sinus of the satellite zenith angle (from $\sin 0^{\circ}=0$ to $\sin 90^{\circ}=1$ ). Colors encode the averaged COT values for a given set of geometries. SZA means solar zenith angle range. There is a poor satellite sampling for relative azimuth angles between $240-300^{\circ}$ for POLDER and between $60-120^{\circ}$ and $240-300^{\circ}$ for MODIS.
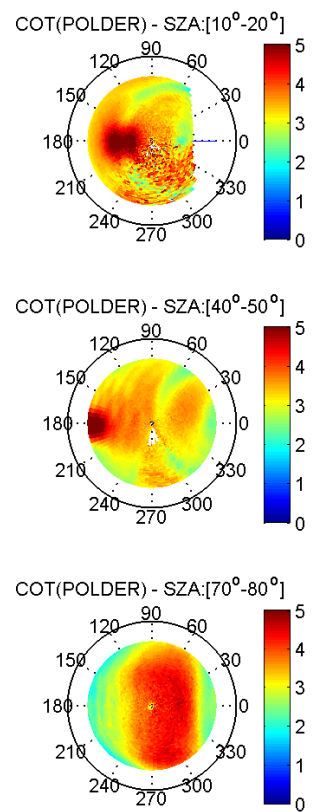
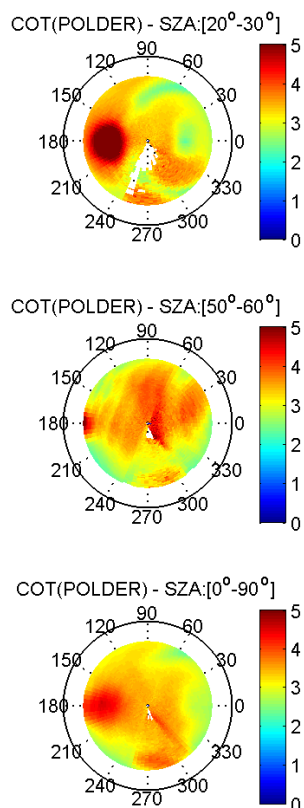
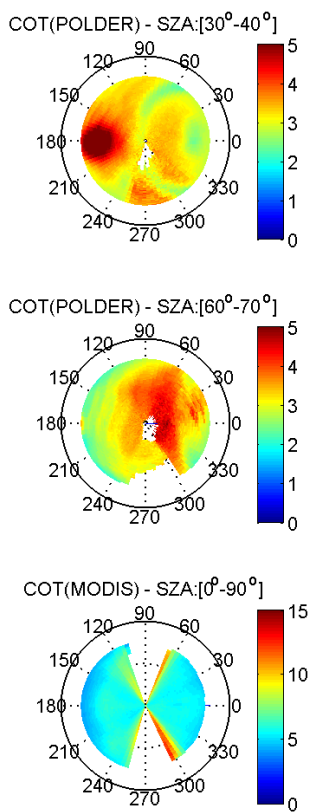

Fig. 9. Polar graphs of POLDER COT for broken oceanic liquid clouds for different solar zenith angles (1st, 2nd lines and the 1st column of the 3rd lines) and of MODIS COT for all sun angles (lower right corner). Polar angle represents relative azimuth angle between the satellite and the sun (from $0^{\circ}$ corresponding to backscattering direction to $359^{\circ}$ ). Polar radius corresponds to the sinus of the satellite zenith angle (from $\sin 0^{\circ}=0$ to $\sin 90^{\circ}=1$ ). Colors encode the averaged COT values for a given set of geometries. SZA means solar zenith angle range. There is a poor satellite sampling for relative azimuth angles between $240-300^{\circ}$ for POLDER and between $60-120^{\circ}$ and $240-300^{\circ}$ for MODIS. 
Table 1. Mean COT computed for the different sun incidences angles represented in the polar graphs in Fig. 8.

\begin{tabular}{rrrrrrrr}
\hline Sun angles & $10-20^{\circ}$ & $20-30^{\circ}$ & $30-40^{\circ}$ & $40-50^{\circ}$ & $50-60^{\circ}$ & $60-70^{\circ}$ & $70-80^{\circ}$ \\
\hline Mean COT & 7.70 & 10.98 & 10.57 & 16.53 & 16.38 & 21.06 & 19.46 \\
\hline
\end{tabular}

corresponds to backward scattering direction. As MODIS observes only in one direction, it has limitations in sampling different relative azimuth angles and figures by class of solar incidence angles are not very informative and thus not presented here. Figures built from POLDER cover more observing geometries that thanks to the 16 observing directions.

For overcast clouds, we note that the angular mean COTs increase with solar zenith angle. We also observed this in Table 1. In this table, mean COTs for each polar graph are computed and increase from 7.70 for high solar elevation to about 20 for low solar elevation. The increase of COT with solar zenith angle on the one hand is due to geographical sampling of an increase of thicker clouds with latitude (Fig. 2) and on the other hand is due to 3-D radiative effects first evidenced by Loeb and Davies (1996) from ERBE observations. They were reproduced with Monte-Carlo simulations by Loeb et al. (1997) and Várnai (2000), which showed a larger increase of 3-D nadir and backward reflectances with solar incidences compared to 1-D ones leading to a retrieved optical thickness, which increases with solar zenith angles. This is explained by side illumination effects due to 3-D cloud structures not accounted for in the plane-parallel cloud approximation used in operational algorithms. In addition, we see clearly that COT values decrease in forward directions $\left(\theta_{\mathrm{s}}>55^{\circ}\right.$ and around $\left.\phi=180^{\circ}\right)$ for both sensors and more markedly for oblique sun. In case of low solar angles between $70-80^{\circ}$, derived COT in forward directions can be as low as $50 \%$ of the angular mean value. This comes partially from the so-called plan-parallel bias. The non-linearity of the reflectance as a function of COT leads to an underestimation of the mean optical thickness (Zinner and Mayer, 2006). At low solar elevation, the plan-parallel bias amplify or limit the shadowing and illumination effects induced by 3 D cloud structures, which respectively decreases or increases the retrieved COT (Várnai, 2000; Várnai and Marshak, 2002; Iwabuchi and Haysaka, 2002). In addition, for low sun, we distinguish a bow with smaller COTs in the cloudbow directions located to about $40^{\circ}$ from the backward directions (i.e., when sun incidence is $60^{\circ}$, cloudbow is situated for $\phi=0^{\circ}$ near $20^{\circ}$ of viewing angle). This is associated to both particle size assumption and cloud inhomogeneities (Buriez et al., 2001).

For broken clouds, we see that MODIS COT decreases with viewing angle (Fig. 9) both in forward and backward directions. This decrease may come from the cloud detection as the MODIS CF increases with the viewing angle (Zeng et al., 2011) because the pixel size increases towards the edges of the scan corresponding to large viewing angles and also because more cloud sides are being seen. As explained in Sect. 4.1, this may result in a decrease of COT with the viewing angle (70-80\% of the angular mean values). For POLDER, we clearly see high values of COT around sunglint directions where the bias can reach up to $100 \%$ of the angular mean values. It points out that the limitation to prevent COT retrieval in sun-glint regions is not conservative enough especially in case of broken clouds (Fig. 9). We also observe in the figure consistent underestimations of COT in backward and cloudbow directions, which are about $75 \%$ of the angular mean values. These underestimations are mainly due to microphysical issues as the POLDER droplet effective radius is set to a constant value.

\section{Conclusions}

In this paper, we studied and compared cloud optical thickness (COT) retrieved from two passive sensors in the A-Train constellation, POLDER/PARASOL and MODIS/AQUA. The accurate retrieval of this parameter strongly depends on many cloud and environment factors such as cloud cover and thermodynamic phase, cloud particle information. After having reminded the main underlying principles of COT retrieval in the POLDER and the MODIS algorithms, we analyzed global geographical distributions, latitudinal variations and seasonal evolutions of COT. This helped to reveal specific uncertainties in COT retrieval. We also studied pixel-topixel relationships of COT between the two sensors, separating clouds by class of phase and cloud fraction determined from a combination of POLDER and MODIS. Our results show that, for overcast clouds with consistent cloud phases, it exists a strong relation between the optical thicknesses of the two sensors. We notice that for liquid clouds, MODIS and POLDER COT have similar values while for ice clouds, the MODIS COT is larger than the POLDER one. For overcast clouds with inconsistent phases, the sensor that employs liquid phase model retrieves larger COT. In case of broken cloud, we concluded that the COT relationships between the two sensors are much weaker. These results between the two optical thicknesses help to indicate in which conditions the retrieved COT can be considered as suitable.

As the second part of this study, we discussed many uncertainties and impacts of various factors in COT retrieval processes. Among all those factors, the sensor spatial resolution is an important one and is first discussed. Through its impact on cloud detection, the spatial resolution differences can bias cloud cover (Zeng et al., 2011) and thus COT. Indeed, 
satellites with lower spatial resolution tend to detect larger cloud cover and yield as a consequence smaller retrieved COT. In addition, the spatial resolution differences lead to different plane-parallel bias due to inhomogeneous clouds. By neglecting the sub-pixel cloud inhomogeneities, satellites with lower spatial resolution will detect smaller optical thickness. Other uncertainties presented are associated to cloud microphysical models used in algorithm. A significant source of uncertainties for COT retrieval lies in the choice of thermodynamic phase, cloud particles size and shape assumptions. Using liquid model instead of ice model leads to an overestimation of COT. The influence of particles size for liquid clouds can be most of the time ignored. However for ice clouds, the differences in the choice of cloud microphysical model used, conduct to the important differences between MODIS and POLDER derived COT. As POLDER does not measure information on particle size, it uses the fixed IHM model, whereas for MODIS, different size and shape distributions were built with effective radius determined from the near infrared band. The comparison of the quantity of scaled optical thickness confirms the phase function used is of primary importance for the determination of the COT for ice clouds. Use of this product allows to account a part of the difference due to microphysical models.

In addition, to study the impact of observation geometry on COT retrieval, we presented angular variations of COT. We clearly see the underestimation of cloud optical thickness in forward directions due to shadow effect especially for the lower sun and also the underestimation of cloud optical thickness from POLDER in cloudbow and backward directions due to the cloud microphysics assumption.

This paper provides a good overview on how COT from passive sensors can be biased. It also provides ground for selection of more confident situations when evaluating cloud representation in models or multi-sensor inter-comparison studies aimed at building climatologic records of cloud properties. Several issues concerning ice cloud microphysics and 3-D radiative effects still need to be explored to obtain better COT values, in particular a better knowledge of ice crystal asymmetry factor is critically needed. In the future, comparisons of cloud top reflectance and clear sky reflectance between POLDER, MODIS and CERES will be done in order to assess the impact of COT biases between different instruments in radiative budget computation.

Acknowledgements. This work was supported by the French Space Agency (CNES) and the Région Nord-Pas de Calais. The POLDER level2 and level3 data were processed and distributed by the French ICARE Data Management and Processing Center (CGTD). The MODIS data were obtained from the NASA/GSFC/LADS. The authors are grateful to CNES and NASA for making the POLDER and MODIS data available.

Edited by: B. Mayer

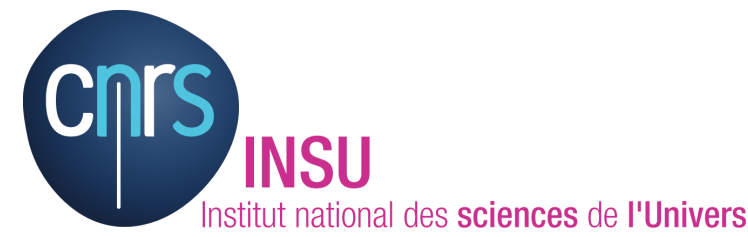

The publication of this article is financed by CNRS-INSU.

\section{References}

Baum, B. A., Yang, P., Heymsfield, A. J., Platnick, S., King, M. D., Hu, Y.-X., and Bedka, S. T.: Bulk scattering properties for the remote sensing of ice clouds. Part II: Narrowband models, J. Appl. Meteor., 44, 1896-1911, 2005.

Buriez, J. C., Vanbauce, C., Parol, F., Goloub, P., Herman, M., Bonnel, B., Fouquart, Y., Couvert, P., and Seze, G.: Cloud detection and derivation of cloud properties from POLDER, Int. J. Remote Sens., 18, 2785-2813, doi:10.1080/014311697217332, 1997.

Buriez, J.-C., Doutriaux-Boucher, M., Parol, F., and Loeb, N. G.: Angular Variability of the Liquid Water Cloud Optical Thickness Retrieved from ADEOS-POLDER, J. Atmos. Sci., 58, 30073018, 2001.

Buriez, J.-C., Parol, F., Cornet, C., and Doutriaux-Boucher, M.: An improved derivation of the top-of-atmosphere albedo from POLDER/ADEOS-2: Narrowband albedos, J. Geophys. Res., 110, D05202, doi:10.1029/2004JD005243, 2005.

Cahalan, R. F.: Bounded cascade clouds: albedo and effective thickness, Nonlin. Processes Geophys., 1, 156-167, doi:10.5194/npg1-156-1994, 1994.

Chang, F.-L. and Coakley, J. A.: Relationships between Marine Stratus Cloud Optical Depth and Temperature: Inferences from AVHRR Observations, J. Climate, 20, 2022-2036, 2006.

C.-Labonnote, L., Brogniez, G., Doutriaux-Boucher, M., Buriez, J.C., Gayet, J.-F., and Chepfer, H.: Modeling of light scattering in cirrus clouds with inhomogeneous hexagonal monocrystals. Comparison with in-situ and ADEOS-POLDER measurements, Geophys. Res. Lett., 27, 113-116, 2000.

C.-Labonnote, L., Brogniez, G., Buriez, J. C., Doutriaux-Boucher, M., Gayet, J.-F., and Macke, A.: Polarized light scattering by inhomogeneous hexagonal monocrystals: Validation with ADEOS-POLDER measurements, J. Geophys. Res., 106, 12139-12153, 2001.

Cox, C. and Munk, W.: Slopes of the sea surface deduced from photographs of the sun glitter, Bull. Scripps Inst. Oceanogr., 6, 401488, 1956.

Deschamps, P., Breon, F., Leroy, M., Podaire, A., Bricaud, A., Buriez, J., and Seze, G.: The POLDER mission: instrument characteristics and scientific objectives, IEEE T. Geosci. Remote Sens., 32, 598-615, 1994.

Han, Q., Rossow, W. B., and Lacis, A. A.: Near-global survey of effective droplet radii in liquid water clouds using ISCCP data, J. Climate, 7, 465-497, 1994.

Heidinger, A. K., Goldberg, M. D., Tarpley, D., Jelenak, A., and Pavolonis, M. J.: A new AVHRR cloud climatology, Proc. SPIE, 5658, 197-205, 2005.

Iwabuchi, H. and Hayasaka, T.: Effects of Cloud Horizontal Inhomogeneity on the Optical Thickness Retrieved from ModerateResolution Satellite Data, J. Atmos. Sci., 59, 2227-2242, 2002. 
Jensen, E. J., Kinne, S., and Toon, O. B.: Tropical cirrus cloud radiative forcing: Sensitivity studies, Geophys. Res. Lett., 21, 20232026, 1994.

King, M. D.: Determination of the Scaled Optical Thickness of Clouds from Reflected Solar Radiation Measurements, J. Atmos. Sci., 44, 1734-1751, 1987.

King, M., Kaufman, Y., Menzel, W., Tanré, D., Center, N., and Greenbelt, M.: Remote sensing of cloud, aerosol, and water vapor properties fromthe moderate resolution imaging spectrometer (MODIS), IEEE T. Geosci. Remote Sens., 30, 2-27, 1992.

Kristiansen, J. and Kristjansson, J. E.: Shortwave cloud forcing of marine stratocumulus clouds, Phys. Chem. Earth Pt. B, 24, 225230, 1999.

Leroy, M., Deuze, J. L., Bréon, F. M., Hautecoeur, O., Herman, M., Buriez, J. C., Tanre, D., Bouffies, S., Chazette, P., and Roujean, J. L.: Retrieval of atmospheric properties and surface bidirectional reflectances over the land from POLDER, J. Geophys. Res., 102, 17023-17037, 1997.

Loeb, N. G. and Coakley, J. A.: Inference of marine stratus cloud optical depths from satellite measurements: does 1d theory apply?, J. Climate, 11, 215-233, 1998.

Loeb, N. G. and Davies, R.: Observational evidence of plane parallel model biases: Apparent dependence of cloud optical depth on solar zenith angle, J. Geophys. Res., 101, 1621-1634, doi:10.1029/95JD03298, 1996.

Loeb, N. G., Várnai, T., and Davies, R.: Effect of cloud inhomogeneities on the solar zenith angle dependence of nadir reflectance, J. Geophys. Res., 102, 9387-9395, doi:10.1029/96JD03719, 1997.

Malkova, V. S.: Use of G. V. Rozenberg's asymptotic expressions for interpretation of cloud brightness measurement, Izv. Acad. Sci. USSR. Atmos. Ocean. Phys., 9, 548-552, 1973.

Mishchenko, M. I., Rossow, W. B., Macke, A., and Lacis, A. A.: Sensitivity of cirrus cloud albedo, bidirectional reflectance and optical thickness retrieval accuracy to ice particle shape, J. Geophys. Res., 101, 16973-16985, 1996.

Mitchell, J. F. B., Senior, C. A., and Ingram, W. J.: $\mathrm{CO}_{2}$ and climate: A missing feedback?, Nature, 341, 132-134, 1989.

Nakajima, T. and King, M. D.: Determination of the optical thickness and effective radius of clouds from reflected solar radiation measurements. Part I: Theory, J. Atmos. Sci., 47, 1878-1893, 1990.

Nakajima, T. Y. and Nakajima, T.: Wide-area determination of cloud microphysical properties from NOAA AVHRR measurements for FIRE and ASTEX regions, J. Atmos. Sci., 52, 4043-4059, 1994.

Parol, F., Buriez, J., Vanbauce, C., Couvert, P., Seze, G., Goloub, P., and Cheinet, S.: First results of the POLDER "Earth Radiation Budget and Clouds" operational algorithm, IEEE T. Geosci. Remote Sens., 37, 1597-1612, 1999.

Parol, F., Descloitres, J., and Fouquart, Y.: Cloud optical thickness and albedo retrievals from bidirectional reflectance measurements of POLDER instruments during ACE-2, Tellus, 52, 888-908, 2000.

Platnick, S. and Valero, F. P. J.: A Validation of a Satellite Cloud Retrieval during ASTEX, J. Atmos. Sci., 52, 2985-3001, 1995.

Platnick, S., King, M., Ackerman, S. A., Menzel, W. P., Baum, B. A., Riedi, J. C., and Frey, R. A.: The MODIS cloud products: algorithms and examples from Terra, IEEE T. Geosci. Remote
Sens., 41, 459-473, 2003.

Riedi, J., Marchant, B., Platnick, S., Baum, B. A., Thieuleux, F., Oudard, C., Parol, F., Nicolas, J.-M., and Dubuisson, P.: Cloud thermodynamic phase inferred from merged POLDER and MODIS data, Atmos. Chem. Phys., 10, 11851-11865, doi:10.5194/acp-10-11851-2010, 2010.

Roebeling, R. A., Feijt, A. J., and Stammes, P.: Cloud property retrievals for climate monitoring: Implications of differences between Spinning Enhanced Visible and Infrared Imager (SEVIRI) on METEOSAT-8 and Advanced Very High Resolution Radiometer (AVHRR) on NOAA-17, J. Geophys. Res., 111, D20210, doi:10.1029/2005JD006990, 2006.

Roeckner, E., Schlese, U., Biercamp, J., and Loewe, P.: Cloud optical depth feedbacks and climate modelling, Nature, 329, 138140, 1987.

Rossow, W. B. and Schiffer, R. A.: ISCCP cloud data products, B. Am. Meteorol. Soc., 71, 2-20, 1991.

Rossow, W. B. and Schiffer, R. A.: Advances in Understanding Clouds from ISCCP, B. Am. Meteorol. Soc., 80, 2261-2287, 1999.

Rossow, W. B., Garder, L. C., and Lacis, A. A.: Global, Seasonal Cloud Variations from Satellite Radiance Measurements. Part I: Sensitivity of Analysis, J. Climate, 2, 419-458, 1989.

Strahler, A. H. and Muller, J.-P.: MODIS Science Team Members: MODIS BRDF/Albedo Product: Algorithm Theoretical Basis Document, Version 5.0, MODIS Product ID: ATBD-MOD-43, 1999.

Szczap, F., Isaka, H., Saute, M., Guillemet, B., and Ioltukhovski, A.: Effective radiative properties of bounded cascade nonabsorbing clouds: Definition of the equivalent homogeneous cloud approximation, J. Geophys. Res., 105, 20617-20633, 2000.

Tselioudis, G. and Rossow, W. B.: Global multiyear variations of optical thickness with temperature in low and cirrus clouds, Geophys. Res. Lett., 21, 2211-2214, 1994.

Várnai, T.: Influence of three-dimensional radiative effects on the spatial distribution of shortwave cloud reflection, J. Atmos. Sci., 57, 216-229, 2000.

Várnai, T. and Marshak, A.: A method for analyzing how various parts of clouds influence each other's brightness, J. Geophys. Res., 108, 4706, doi:10.1029/2003JD003561, 2002.

Waquet, F., Riedi, J., Labonnote, L. C., Goloub, P., Cairns, B., Deuzé, J.-L., and Tanré, D.: Aerosol remote sensing over clouds using a-train observations, J. Atmos. Sci., 66, 2468-2480, 2009.

Warren, S. G., Hahn, C. J., London, J., Chervin, R. M., and Jenne, R. L.: Global distribution of total cloud cover and cloud type amounts over land, NCAR Technical Note, NCAR/TN273+STR, National Center for Atmospheric Research, Boulder, Colorado, 1986.

Warren, S. G., Hahn, C. J., London, J., Chervin, R. M., and Jenne, R. L.: Global distribution of total cloud cover and cloud type amounts over the ocean, NCAR Technical Note, NCAR/TN317+STR, National Center for Atmospheric Research, Boulder, Colorado, 1988.

Zeng, S.: Statistical comparison of cloud properties derived from POLDER/PARASOL and MODIS/AQUA in the A-Train constellation, Ph.D. thesis, Lille1 University, Villeneuve d'Ascq, France, 2011.

Zeng, S., Parol, F., Riedi, J., Cornet, C., and Thieuleux, F.: Examination of POLDER/PARASOL and MODIS/AQUA Cloud 
Fractions and Properties Representativeness, J. Climate, 24, 4434-4449, doi:10.1175/2011JCLI3857.1, 2011.

Zhang, Z., Yang, P., Kattawar, G., Riedi, J., C.-Labonnote, C., Baum, B. A., Platnick, S., and Huang, H.-L.: Influence of ice particle model on satellite ice cloud retrieval: lessons learned from MODIS and POLDER cloud product comparison, Atmos. Chem. Phys., 9, 7115-7129, doi:10.5194/acp-9-7115-2009, 2009.
Zinner, T. and Mayer, B.: Remote sensing of stratocumulus clouds: Uncertainties and biases due to inhomogeneity, J. Geophys. Res., 111, D14209, doi:10.1029/2005JD006955, 2006. 